\title{
A reforma do Estado, a emergência da descentralização e as políticas ambientais
}

\author{
Andréa Azevedo, Richard Pasquis e Marcel Bursatyn
}

\section{Introdução}

Diversas mudanças aconteceram no papel do Estado no final do século XX. O modelo centralizador e protetor entra em crise e isso leva não a uma reforma no primeiro momento, mas a um recuo do Estado em seu papel de comando e controle. A retirada foi rápida e intensa, deixando ao mercado um amplo espaço de atuação. Contudo, a prevalência da lógica do Estado mínimo revelou que o mercado não consegue ser equânime em suas alocações e suas imperfeições provocaram reações por parte de diferentes segmentos da sociedade. Essa reação serviu de pano de fundo para um debate sobre reforma do Estado. Ficava claro que ele precisaria ser forte, sim, mas não tão grande, nem soberano como antes, tampouco tão mínimo como queriam os neoliberais. A medida certa poderia se encaixar na denominação Estado social-liberal (Bresser Pereira, 2001).

Essa reforma do Estado ainda está em processo, e o modelo do "Estado em rede", concebido para um contexto globalizado e informatizado, parece ser o 
que mais tem despertado interesse. Idealmente, parece ser um Estado mais leve, menos centralizado, mais flexível, com mais espaços para a sociedade civil na sua forma de atuação.

A busca da descentralização e da maior participação nas políticas públicas indica uma possibilidade de re-legitimação desse Estado que padece de mazelas inerentes às práticas enraizadas na democracia representativa. Os eleitores não se reconhecem nos seus eleitos, pelo contrário, perdem a confiança na democracia representativa como vetor de mudança. Nesse sentido, o Estado em rede exerce um apelo interessante, pois permite juntar os aspectos inerentes ao nível global aos anseios locais. O centro não é tão definido como antes, e as pessoas se sentem mais perto das decisões políticas. Essa cidadania mais ativa pode ser um vetor de legitimação do Estado em todas as esferas.

No Brasil, o processo de descentralização política e a participação da população já vêm acontecendo há algum tempo, ganhando mais espaço na década de 1990. Na área ambiental, a Constituição Federal de 1988 deu um grande impulso para esse desfecho, mas ainda caminha em passos mais lentos. Contudo, parece ser um caminho inexorável e o número de municípios com órgãos ligados ao meio ambiente cresce a cada dia.

Deve-se notar que o processo ideal de descentralização está atrelado a outros aspectos, como capacidade institucional e administrativa local, controle social, mecanismos de flexibilização, mas, sobretudo, é de suma importância que o processo ocorra de forma compartilhada com outras instâncias e esferas do governo.

Esse parece ter sido um problema na descentralização da política ambiental no Brasil. Há uma certa ausência de responsabilidades nessa transferência. Isso pode ser muito prejudicial, pois um círculo nada virtuoso pode se formar com a esfera federal, que passa a imagem de descontrole, bem como com a regional e a local, que passam a idéia de inoperância e incompetência.

Assim, duas questões serão discutidas neste artigo:

- em que medida a descentralização não vem sendo interpretada de maneira estreita, ou seja, mais como uma transferência total de responsabilidade (sem recursos) do governo central (no sentido vertical), do que propriamente um compartilhamento com os estados e municípios de sua competência legislativa e administrativa?

- em que medida o princípio da subsidiariedade está sendo realmente aplicado como deveria (como aquele em que a regulação pública deve se dar no nível menos centralizado possível) e não como uma omissão do governo federal diante de ações que as esferas estaduais e municipais não têm capacidade/governança para efetuar?

A hipótese para esse trabalho é que a descentralização ambiental está sendo forçada de cima para baixo, sem observarse a capacidade de governança dos subníveis estadual e local em muitas ocasiões, o que contribui para corroer a legitimidade dos governos locais. Além disso, o governo federal exerce apenas minimamente a função de coordenador do processo, dentro desse papel de transferência de competências e de criador de novos espaços conjuntos de gestão descentralizada.

Com o objetivo de discutir essas questões, o artigo está estruturado em três seções principais, além da introdução e da conclusão. A primeira analisa a 
configuração desse Estado em reforma e a execução das políticas públicas dentro desse novo contexto. A segunda apresenta alguns princípios desse Estado, com especial atenção para a subsidiariedade, mas também considera a coordenação e a participação. A terceira trata alguns elementos empíricos para análise da descentralização das políticas ambientais no Brasil, focando o instrumento do licenciamento em dois contextos: no espaço urbano e no rural. No espaço urbano, discute-se o aparato institucional que têm os municípios na área ambiental. A fonte de dados foi o relatório do perfil dos municípios brasileiros, do Instituto Brasileiro de Geografia e Estatística (IBGE); no rural, são levantadas algumas considerações sobre a gestão florestal ocorrida no Mato Grosso, que foi o primeiro estado da Amazônia Legal a ter o processo integral de descentralização dessa função regulatória.

As políticas públicas dentro de uma nova configuração do Estado

Fazendo uma breve retrospectiva da intervenção do Estado na sociedade, observa-se que a demanda social por políticas e ações governamentais é antiga. No entanto, ao final do século XIX, fechando um ciclo liberal, desenhou-se um cenário para um Estado cada vez mais atuante. Isso implicou uma expansão burocrática, com o surgimento de novas pastas ministeriais e novos quadros de funcionários.

Bursztyn (1998) comenta que apenas as antigas pastas das finanças (arrecadação) e justiça (polícia) já não eram mais suficientes diante das mudanças provocadas após a revolução francesa, sobretudo com o advento da industrialização, embalada pelas idéias iluministas. A Alemanha de Bismarck é um caso emblemático da vanguarda nas políticas sociais. De forma geral, diversos países europeus seguiram o modelo que culminou em meados do século XX com a reprodução em grande escala do Estado de bem-estar (welfare state). É importante lembrar que o Estado nos países periféricos, denominado por alguns de desenvolvimentista, embora tenha adotado alguns dos instrumentos que caracterizam as

“A descentralização não estaria sendo interpretada como uma transferência total de responsabilidade (sem recursos) do governo central (no sentido vertical), do que propriamente um compartilbamento com os estados $e$ municípios de sua competência legislativa e administrativa?”

políticas de bem-estar, nunca conseguiu universalizar essas políticas sociais.

Com a crise do Estado de bem-estar, provocada, em grande medida, pelo envelhecimento da população, a conseqüente demanda por mais seguridade, além da crescente falta de emprego estrutural gerada por mudanças tecnológicas, a fisionomia desse Estado keynesiano passa por mudanças profundas a partir da 
década de 1970. O remédio para aliviar a pressão sobre esse Estado "pesado", foi o "consenso de Washington", que pregava a abertura econômica e a liberalização do Estado de suas antigas funções. Essa seria a tônica desse novo Estado, mais leve, mais "desonerado", em um contexto em que as trocas livres das barreiras comerciais inter-países com a mínima interferência do Estado-nacional seria condição essencial para a continuidade do capitalismo democrático e "liberal".

No entanto, os equívocos entre desestatização e desregulação foram muitos. Quando se privatiza alguns bens e serviços importantes à sociedade, mais do que nunca o Estado deve estar preparado para regular essas ações, mesmo não sendo ele quem as pratica diretamente. Ele deve passar a regular por meio das regulamentações. Dessa forma, se as regulamentações não servem mais ou estão anacrônicas, o Estado deve promover uma "re-regulamentação”, como afirma Bursztyn (1998).

O enfraquecimento do Estado mostrou-se inoperante diante de problemas que emergiram desse processo. Boaventura de Souza Santos (1998) reitera que os dilemas do consenso de Washington foram revelados a partir de sucessivas crises em países periféricos, além da generalizada corrupção política e reaparecimento das máfias. Segundo o autor, o problema não se resolve com a redução da "quantidade de Estado". Ele indica a necessidade de reformar a "qualidade do Estado", partindo da idéia de que Ele é reformável.

Bresser Pereira (1998) indica que esse novo Estado que emerge no século XXI deve ser menor, porém mais forte, com maior governabilidade e governança ${ }^{1}$. É um ente mais fomentador do que propriamente executor, menos protetor $\mathrm{da}$ economia nacional e mais estimulador $\mathrm{da}$ competitividade internacional. O autor denomina esse Estado (reformado) como Estado social-liberal: social, porque continuará protegendo direitos sociais e promovendo o desenvolvimento econômico; liberal, porque o fará utilizando mais controles de mercado, do que propriamente administrativos, porque realizará suas atividades sociais e científicas notadamente por meio de instituições públicas não estatais (também denominado terceiro setor).

Moran (2002) faz a revisão de uma ampla literatura, que trata da regulação do Estado, trazendo, casos mais específicos da regulação americana e britânica. Segundo o autor, grande parte da literatura consultada compartilha a preocupação com uma "crise do comando", por um lado, com a crise do controle na economia pela via pública direta e, por outro, com o colapso do que muitas vezes se chama auto-regulação ${ }^{2}$. $\mathrm{O}$ autor questiona se o "Estado regulador" existe e em que ele consiste. Ao final, conclui que há três vias (dentro da literatura da ciência política) para essa resposta: a primeira é que a regulação é uma ficção; a segunda é que o Estado regulador existe, mas seu caráter é contingente, dependendo do contexto nacional; e a terceira está mais ligada ao recente paradigma de governança, no qual governar significa mais manejar/ coordenar redes do que propriamente comandar/pilotar um "grande navio" chamado Estado.

Parece que o grande desafio que se coloca é o equilíbrio entre esse Estado social e liberal, que passa pela verificação de áreas que ainda precisam de regulamentações mais pesadas. Bresser Pereira (1998) assume que, mesmo com a reforma do Estado apontando na direção substancial da redução da regulação, não se pode pensar na sua eliminação. "Em muitas áreas, o Estado continua tendo um papel regulador 
significativo, como no caso do comércio exterior e controle ambiental" (p.7).

Diferentes reformas os Estados estão em curso no momento, umas em estágios mais avançados, outras nem tanto. A idéia de Estado em rede é uma dessas possibilidades que se vislumbra no panorama político mundial. A descentralização justificada pelo princípio da subsidiariedade na gestão é a tônica desse Estado reformado. No entanto, Castells (1998) chama atenção para a importância da coordenação do Estadonação dentro dessa nova configuração, que deixa de ter as características anteriores, mas não o elimina. Em síntese, redefine-o.

Esse Estado-rede caracteriza-se por compartilhar a autoridade (a capacidade institucional de impor uma decisão) ao longo de uma rede de instituições. "Uma rede, por definição, não tem centro, mas nós de diferentes dimensões e com relações entrenós que são freqüentemente assimétricas" (CAstells, 1998, p.11; grifo nosso). Em última instância, todos os nós são necessários para a existência da rede. Segundo o autor, o Estado-rede corresponde a uma expressão da era da informação: é a "forma política que permite a gestão cotidiana da tensão entre o local e o global" (ibid.).

Dentro desse contexto do Estado em rede, vários princípios são recomendados para sua concretização ${ }^{3}$. Será abordado de maneira mais direta o princípio da subsidiariedade, que norteia a descentralização e os diversos aspectos que a caracterizam.

\section{Descentralização: um processo de muitas faces}

Conceitualmente, é preciso diferenciar desconcentração de descentralização. $\mathrm{O}$ primeiro é o compartilhamento das funções com as subsidiárias regionais e locais, sob um poder de comando obedecendo a uma hierarquia do nível central. O segundo, a descentralização, envolve a transferência de autoridade e as respectivas competências legais e administrativas para outra instância de governo, seja de nível estadual, seja municipal (AzEvEDo; SCARDUA, 2006).

Dentro da idéia de Estado em rede, o princípio que norteia a descentralização é o da subsidiariedade. Segundo Jordan (2000, p.2), que estuda esse processo no contexto da União Européia, "subsidiariedade é um princípio do governo federal que diz que determinada ação deve ser tomada no nível mais descentralizado desde que seja consistente com uma ação efetiva". Apesar de ser um conceito antigo, foi incorporado no mainstream político europeu no início da década de 1990. O autor indica que, na origem, subsidiariedade é um termo federal, usado para alocar poder entre diferentes níveis de governo.

CASTELLS (1998) argumenta que o nível mais adequado para determinada competência é uma discussão muito mais política que técnica e que ele é modelado de acordo com os momentos históricos das distintas sociedades. O essencial, segundo o autor, "é proceder uma ampla descentralização em que se transfira poder e recursos aos níveis mais próximos dos cidadãos e seus problemas" (p.16, grifo nosso). No limite, o princípio da subsidiariedade permite a transferência de responsabilidades executivas do Estado para a própria sociedade e mesmo para empresas, em tudo aquilo que o Estado não seja necessário como executor direto. Isso significa que o princípio da subsidiariedade é aquele que norteia o processo de descentralização.

Mas por que há necessidade de descentralizar? O autor ainda postula que existem duas forças que levam para esse 
caminho: a resposta do Estado às reivindicações locais e regionais e às expressões coletivas identitárias, de um lado, e "um esforço consciente do Estado-nação de encontrar fórmulas alternativas frente à rigidez da centralização e à crise de legitimidade que emana da desconfiança dos cidadãos", de outro. (CASTELls, 1998, p. 9).

Assim, percebe-se que a descentralização, dentro de um Estado que perde sua legitimidade justamente por não conseguir cumprir suas funções sociais e tampouco promover o desenvolvimento econômico, é um instrumento que tenta recuperar seu poder de governabilidade, entendida aqui como legitimidade para tomar decisões políticas. Com a execução das políticas públicas ficando mais próxima dos cidadãos afetados, os espaços de participação tendem a ficar mais evidentes para a população, que se sente com mais direito de intervir.

Fica patente, então, o papel da sociedade para que esse processo aconteça. $\mathrm{O}$ que, a princípio, parece uma simples transferência de poder, começa a ganhar maior complexidade, levando-se à formulação de alguns questionamentos sobre como assegurar que essa população vá participar. Ou, indo mais direto ao ponto, como garantir uma participação que seja desencadeada por e desencadeadora de um processo de autonomia democrática e fortalecimento da cidadania e não de simples legitimação ou cooptação dos/ pelos poderes locais?

Castells (1998) argumenta que a experiência desmente a visão romântica do local como âmbito de democracia e participação. Governos locais e estaduais, em todo o mundo, são freqüentemente os níveis mais corruptos da administração, entre outras razões, porque as redes pessoais mantêm-se com mais força do que no nível federal e assumem competências do urbanismo e da gestão do solo, setores de atividade mais suscetíveis à captura da administração por interesses privados. De toda forma, segundo o autor, evidências empíricas (em outros trabalhos realizados por $\mathrm{ele}^{4}$ ) parecem demonstrar que a proximidade do governo e dos cidadãos no âmbito local permite um controle social mais transparente e reforça as oportunidades de participação política e, no limite, de re-legitimação do Estado.

A outra face da problemática da participação nos espaços institucionalmente criados está na legitimidade dessa representação. Para citar um exemplo simples, quais e quantos são os atores representados nos diversos conselhos espalhados pelo País? Considerando que grande parte dos 5.560 municípios brasileiros tem menos que 20 mil habitantes, esses "líderes locais", intitulados de representantes da sociedade civil, correm o risco de estarem representando não mais do que eles próprios (!), além da forte probabilidade de se revezarem muito pouco na diversidade de conselhos que se apresenta no cenário político do Brasil. Soma-se a isso a "qualidade política" ${ }^{2}$ desses cidadãos que se encontram nesses espaços institucionalizados de participação.

Toda essa questão relativa à participação é uma face que deve ser cuidadosamente apreciada quando se fala em descentralização. Não se quer fazer neste texto uma exortação da não-participação ou do não-conselho ou da não-descentralização. O que se pretende é levantar pontos problemáticos e que parecem estar, em alguns momentos, em um plano subjetivo de reflexão. O intuito é desmitificar que a descentralização seja a solução de problemas historicamente fundados na 
sociedade brasileira e que agora seriam resolvidos com a simples mudança do âmbito de atuação. Esse contraponto é tão relevante quanto a constatação de que o Brasil tem uma história política e institucional fortemente marcada por mazelas como o clientelismo, o coronelismo, o fisiologismo e o patrimonialismo.

Outra face da descentralização é a do poder central ou federal. Um dos obstáculos à descentralização comumente citado é a resistência do poder central à perda de poder. Pensando no Estado-nação, as estratégias adotadas por ele para aumentar sua operatividade (mediante a cooperação internacional) e para recobrar sua legitimidade (mediante a descentralização e autonomia) acabam realmente aprofundando suas crises, pois, ao colocá-las em prática, ele perde poder, competências e autonomia em beneficio dos niveis supranacional e subnacional. Por isso a "importância de acompanhar o processo de redistribuição de competências e recursos por meio de mecanismos de coordenação entre os distintos níveis institucionais em que se desenvolvem as ações dos agentes políticos" (CASTELLs, 1998, p.9, grifos nossos).

Talvez, esse papel de coordenação deva ser melhor evidenciado no processo, seja para não causar essa impressão, muitas vezes, de desregulação e/ou descontrole do Estado no âmbito federal, seja para que o processo de descentralização resulte realmente em melhoria na operacionalização das políticas públicas. Nesse ponto, é relevante ressaltar a idéia de capacidade de governança e de apropriação do nível da descentralização (nível de subsidiariedade). Retomando o conceito de governança como aquele em que o Estado (em qualquer nível) tem capacidade financeira e administrativa para implementar suas políticas de subsidiariedade como aquele que revela o nível em que se desenvolve uma ação (do governo) com efetividade, pode-se chegar a um pressuposto: o nivel escolhido para que a subsidiariedade possa ser aplicada deverá ser aquele que tem capacidade de governança, ou seja, prescinde de sustentabilidade institucional.

Isso parece óbvio, mas na prática os processos não têm sido construídos necessariamente dessa maneira, sobretudo no âmbito da política ambiental. Ao contrário disso, primeiro se descentraliza a competência e depois se criam (quando criam) as condições de governança. Godard (1997) comenta que essa transferência de poder central para regional/local pode ser entendida como simplesmente uma forma das regiões/estados se destutelarem do Estado central. Considerando a idéia do autor, pode-se também pensar o contrário: que a descentralização pode ser uma forma de omissão do poder central.

No entanto, Godard argumenta que o enfoque não deveria ser esse. $\mathrm{O}$ sentido de descentralização deve ser entendido como o estabelecimento de novas relacõoes entre os diversos niveis, "limitando-se as zonas de responsabilidade exclusiva e ampliando-se as de responsabilidade conjunta” (p. 238, grifos nossos). A cooperação entre os níveis deve existir sempre, mesmo que cada um tenha um papel definido a desempenhar.

$\mathrm{Na}$ próxima seção, será examinado, com alguns dados empíricos, o processo de descentralização da política ambiental no Brasil e seus desafios.

\section{A descentralização da política ambiental no Brasil}

Um ponto de inflexão que merece destaque na institucionalização da política ambiental brasileira verifica-se após a Conferência das Nações Unidas sobre Desenvolvimento Humano, realizada em 
1972, em Estocolmo. Mesmo cumprindo mais um papel formal no período inicial, em 1973 foi criada a Secretaria Especial de Meio Ambiente (Sema), ligada à Presidência da República. Foi o primeiro órgão instituído na esfera federal especificamente para lidar com as questões ambientais.

Somente em 1981 foi criada a Política Nacional de Meio Ambiente (PNMA), Lei 6.938, que estabelecia o Sistema Nacional de Meio Ambiente (Sisnama). Esse sistema integra as três esferas do governo: federal, estadual e municipal, bem como, dentro de cada esfera, separa as competências entre as arenas política, executiva e judiciária. Além disso, a grande novidade foi a criação de conselhos consultivos e deliberativos em cada uma das esferas, iniciando um processo de democracia representativa, que antes inexistia nessa área (Bursztyn; Bursztyn, 2000). A Tabela 1 resume a composição do Sisnama, indicando as competências nas três esferas.

Percebe-se, assim, que a PNMA de 1981 abre caminho para dois pontos fundamentais: a descentralização da gestão e a participação social institucionalizada. Ainda contribuindo para o contexto da regulamentação ambiental no Brasil, é importante destacar a Lei dos Interesses Difusos (Lei 7.347/85) e a Constituição Federal de 1988 como dois marcos do aumento na democratização da política ambiental. A Constituição de 1988, em particular, trouxe vários avanços no que concerne à questão ambiental, como um capítulo exclusivo sobre o tema. Além disso, elevou os municípios à categoria de unidade federativa e estabeleceu a "repartição de competências e a previsão do direito do meio ambiente" (SCARDUA; Bursztyn, 2003, p. 302).

Mesmo com esses novos arranjos institucionais, a descentralização na gestão ambiental no Brasil é marcada por oscilações. Ela é incorporada à Política Nacional de Meio Ambiente em 1981, definha com a criação do Ibama em 1989 e é retomada na segunda metade dos anos 1990, junto com uma tendência política, nacional e internacional, nessa direção.

Em algumas áreas, a política ambiental no Brasil está mais avançada em relação à descentralização. Uma delas é o licenciamento, que já fazia parte do cenário das políticas ambientais bem antes da Consti-

\section{Tabela 1: O Sisnama e suas competências}

\begin{tabular}{l|l|l|l}
\hline & Esfera federal & Esfera estadual & Esfera municipal \\
\hline $\begin{array}{l}\text { Elaboração de } \\
\text { políticas }\end{array}$ & $\begin{array}{l}\text { Ministério do Meio } \\
\text { Ambiente (MMA) }\end{array}$ & $\begin{array}{l}\text { Secretarias estaduais } \\
\text { de meio ambiente }\end{array}$ & $\begin{array}{l}\text { Secretarias municipais } \\
\text { de meio ambiente }\end{array}$ \\
\hline $\begin{array}{l}\text { Participação da } \\
\text { sociedade }\end{array}$ & Conama & Consema & Consema \\
\hline $\begin{array}{l}\text { Execução das } \\
\text { políticas }\end{array}$ & Ibama $^{6}$ & Oema & $\begin{array}{l}\text { Agências municipais de } \\
\text { meio ambiente }\end{array}$ \\
\hline Arena jurídica & $\begin{array}{l}\text { Procuradoria Federal } \\
\text { e Ministério Público } \\
\text { Federal }\end{array}$ & $\begin{array}{l}\text { Procuradoria Estadual } \\
\text { e Ministério Público } \\
\text { Federal }\end{array}$ & $\begin{array}{l}\text { Juizado volante } \\
\text { ambiental; Ministério } \\
\text { Público }\end{array}$ \\
\hline
\end{tabular}

Fonte: Bursztyn; Bursztyn, 2000. 
tuição de 1988, sobretudo em estados como Rio de Janeiro, São Paulo e Minas Gerais onde essa obrigatoriedade constava na legislação estadual. O licenciamento tornouse obrigatório em todo País em 1983 após a regulamentação da lei federal 6.938/81 (Política Nacional de Meio Ambiente) pelo decreto 88.351 (Oliveira, 2005).

A primeira lei prevendo o licenciamento no Brasil foi de São Paulo (Lei 997 de 31/5/1976), mas o primeiro a estabelecer um Sistema de Licenciamento de Atividades Poluidoras (SLAP) foi o Rio de Janeiro, por meio de um Decreto-lei de 1975, que só foi regulamentado em 1977. Como se percebe, esse instrumento nasce descentralizado.

Em relação à competência legislativa, a Constituição Federal, em seu artigo 24, atribui à União, aos estados e aos municípios poder de legislar concorrentemente em matéria ambiental. Contudo, essa competência fica limitada aos municípios em caráter suplementar, ou seja, quando o assunto for de interesse eminentemente local. Mesmo assim, deve se enquadrar à legislação dos demais entes.

No caso do governo federal e dos estados, a competência é concorrente, devendo o primeiro estabelecer as normas gerais e os últimos, as complementares. Em relação à competência administrativa on executiva, os entes federativos possuem competência comum (FINK et al, 2004). A transferência de atribuições acontece por meio dos pactos federativos e convênios. No entanto, alguns requisitos básicos são necessários ao nível administrativo competente. No caso, o estado e/ou município, para exercer a competência administrativa, deve ter uma secretaria, um código e um fundo, além de um conselho, todos ligados à área ambiental.

No Brasil, segundo o estudo Perfil dos Municípios, do IBGE (2004), 71\% dos
5.560 municípios possuem alguma estrutura formal de meio ambiente ligada à prefeitura (Gráfico 1), o que não implica necessariamente descentralização de funções que antes eram do estado ou do governo federal. No entanto, é um bom indicador para avaliar que essa preocupação chegou à pauta da maioria das administrações municipais.

Quando se observa no Gráfico 1 o número de municípios que efetivamente

\begin{tabular}{l}
\multicolumn{1}{c}{ “A realidade da } \\
descentralização \\
é distante da maioria \\
dos municípios \\
brasileiros, \\
sobretudo em \\
estados onde a \\
preocupação \\
ambiental ainda é \\
vista por muitos \\
políticos locais \\
como entrave ao \\
desenvolvimento \\
econômico."
\end{tabular}

têm uma secretaria específica de meio ambiente - portanto dispõe de um orçamento próprio para área -, percebese que essa quantidade é bem reduzida (mesmo tendo aumentado de 2002 a 2004), perfazendo, em 2004, cerca de 7\%. Cabe assinalar que o fato de dispor de uma secretaria exclusiva não significa que a gestão seja descentralizada e tampouco indica a qualidade dessa gestão. Dentro do 


\section{Gráfico 1: Número de municípios brasileiros com estrutura formal na prefeitura na área de meio ambiente (2002-2004)}

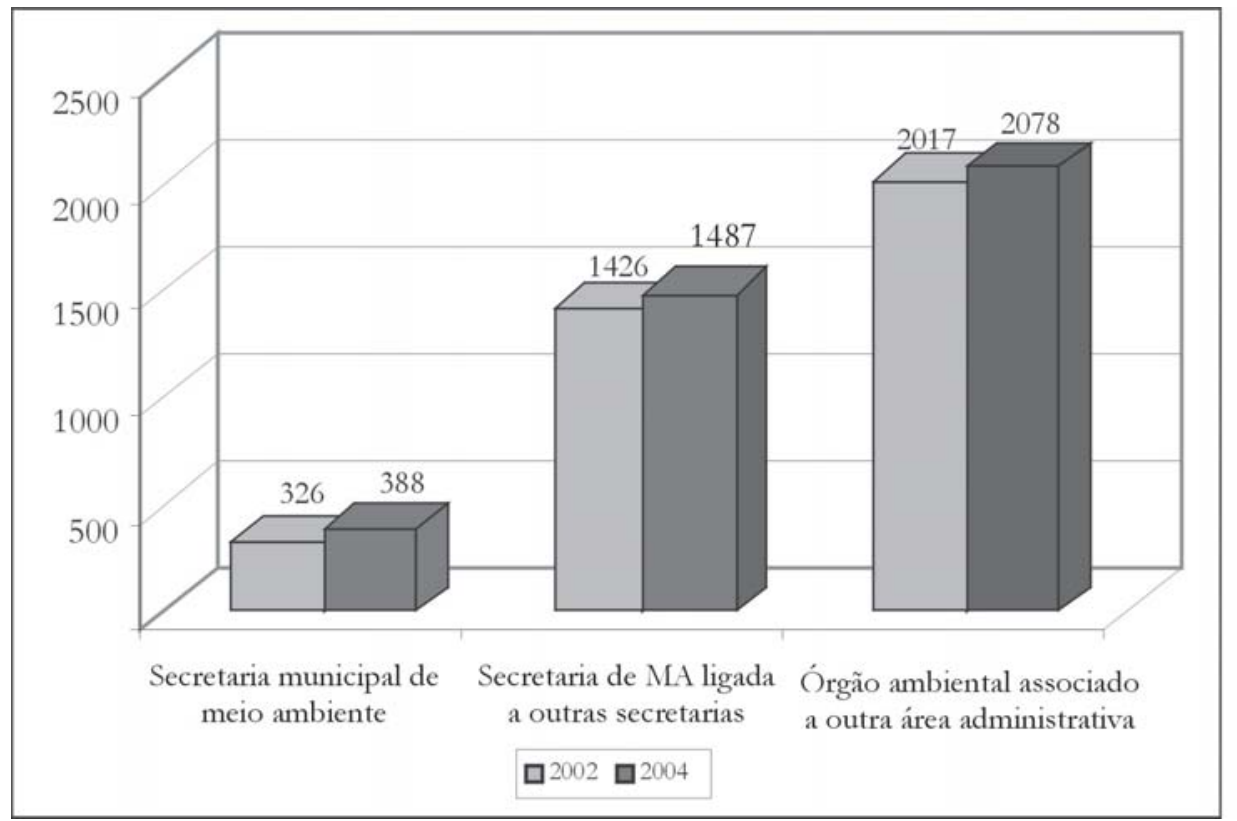

Fonte: IBGE, Perfil dos municípios brasileiros, 2004, p. 69.

Estado do Mato Grosso, por exemplo, dos seus 141 municípios, alguns deles com secretarias exclusivas, somente o de Cuiabá, a capital do estado, exerce a competência para licenciar empreendimentos de baixo impacto na área urbana.

Esse exemplo ilustra o quanto a realidade da descentralização é distante da maioria dos municípios brasileiros, sobretudo em estados onde a preocupação ambiental ainda é vista por muitos políticos locais como entrave ao desenvolvimento econômico.

Algumas razões poderiam ser elencadas para explicar a lentidão e a falta de interesse dos municípios, sobretudo em estados menos industrializados, em assumir a competência para o licenciamento. Primeiro, os municípios não têm empreendimentos suficientes para assegurar a sustentabilidade econômica da secretaria; segundo, mesmo que os tenha, é um desgaste político para o governo local, que irá impor mais um ônus ao empreendedor; terceiro, a municipalidade não quer ou não pode arcar com mão-deobra mais qualificada de técnicos para avaliação dos processos de licenciamento; e quarto, a estrutura para a fiscalização é muito mais restrita e fácil de ser cooptada pelos poderes locais. Resumidamente, a solução via descentralização das políticas ambientais passa por fragilidades institucionais (incluindo a política local), financeiras e administrativas (SCARDUA; BURSZTYN, 2003). Em outras palavras, a governança para a descentralização da gestão ambiental no Brasil ainda não é uma idéia concreta em boa parte dos municípios brasileiros.

Colocando os conselhos municipais de meio ambiente em números, verifica-se um crescimento gradual desse espaço de participação na política ambiental, como mostra o Gráfico 2. 
Gráfico 2: Porcentagem de municípios com conselho de meio ambiente ativo (dinâmica entre 2001 e 2004)

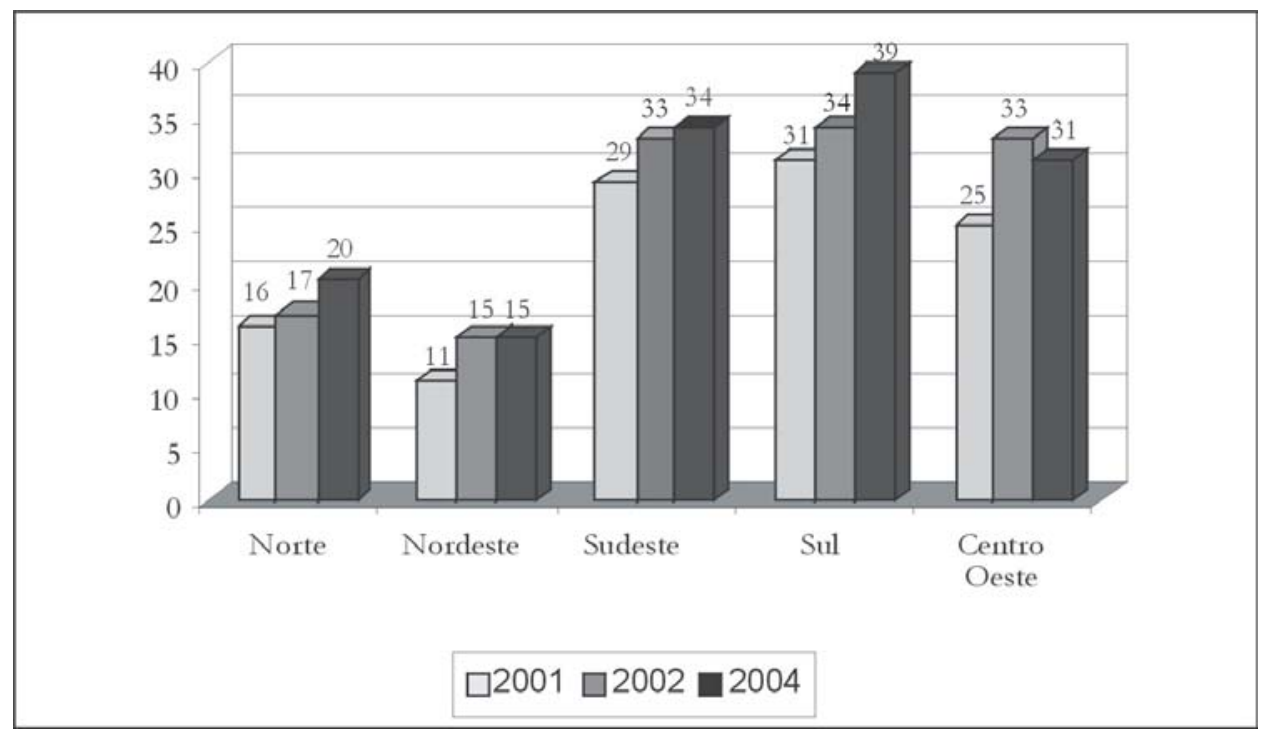

Fonte: IBGE, Perfil dos municípios brasileiros, 2004, p. 69.

Nota-se um crescimento maior dos conselhos na região Sul do País e um decréscimo na região Centro-Oeste. Não há informações disponíveis que permitam explicar esses números, mas, como hipótese para futuras investigações, pode-se imaginar um capital social mais consolidado no Sul, inclusive com mais entidades e organizações do terceiro setor, que geralmente demandam a criação das secretarias e conselhos. Uma outra explicação pode ser a maior quantidade de disputas pelos recursos naturais que, na região Sul, já estão mais escassos que no Centro-Oeste, por exemplo.

Em relação ao papel do terceiro setor nesse processo, Santos (1998, p. 16) observa que este visa forçar a abertura de espaços de democracia participativa em situações em que a democracia representativa é de baixa intensidade. Segundo o autor, essa pode ser a forma mais eficaz de o terceiro setor contribuir para a reforma solidária e participativa do Estado. Contudo, o autor argumenta que é necessária uma profunda democratização do terceiro setor; caso contrário, será um erro confiar-lhe a tarefa de democratização do Estado e, de forma mais geral, do espaço público não-estatal. Reforçando o último argumento, ele acrescenta que "existem diversas experiências mostrando a promiscuidade antidemocrática entre Estado e terceiro setor, em que o autoritarismo centralizado do Estado se apóia no autoritarismo descentralizado do terceiro setor e cada um deles usa o outro como álibi para se desresponsabilizar diante dos seus respectivos constituintes" (p. 16, grifo nosso).

Outra instância que surgiu no cenário da política ambiental brasileira são as comissões tripartites. Essas comissões são constituídas por representações paritárias dos órgãos e entidades ambientais com o objetivo de "constituir um espaço institucional de diálogo entre os entes 
federados com vistas a uma gestão compartilhada e descentralizada entre União, estados e municípios [...]" (Portaria Federal 473, de 9/12/2003). Ainda é cedo para avaliar o papel efetivamente desempenhado na descentralização por essas comissões, mas o que se nota são reforços institucionais na concretização desse processo. Além do esforço do governo, existem associações, como a Associação Nacional de Municípios e Meio Ambiente (Anama), que militam a favor da descentralização da gestão ambiental para os municípios.

\section{Exemplo da experiência de descentralização florestal no Estado do Mato Grosso}

A gestão florestal é um tema que merece comentários no aspecto da descentralização. Scardua (2003) esclarece que, apesar da existência de um marco legal para o setor, desde 1934, não foi possível o avanço institucional e legal nessa área no País, como em outras na política ambiental brasileira $^{7}$. Isso porque a gestão dos recursos florestais no Brasil é altamente centralizada, fruto de uma política federal herdada do início do século passado. Em 2002, já existiam 18 estados com políticas florestais próprias. Entretanto, pode-se observar que a região Norte, que apresenta o maior potencial florestal, é a que mais carece de instrumentos de gestão florestal estadual, sendo que alguns estados não apresentam sequer uma política para o setor (SCARDUA, 2003).

O exemplo do caso da descentralização florestal no Mato Grosso é bastante esclarecedor sobre a importância da presença do âmbito federal nesse processo. Inicialmente, em 1999, foi assinado um pacto federativo, e a função de licenciamento de propriedades rurais e autorização para desmatamento foram passadas para o estado. O Mato Grosso, na época, implementou um sistema de licenciamento sofisticado tecnologicamente, que envolvia a utilização de Sistema de Geo-referenciamento para monitorar o cumprimento do Código Florestal.

O Licenciamento Ambiental Único (LAU) gerou boas expectativas em relação ao seu êxito, sobretudo, no meio científico e entre ambientalistas. Em um ano (20002001), houve redução de $24 \%$ na taxa de desmatamento e 53\% no número de queimadas. Em 2002, os números do desmatamento reduziram-se mais ainda. A Tabela 2 mostra as médias de desmatamento nesse período:

No ano de 2002, esses números eram de 795 mil ha. No entanto, contrariando as expectativas de declínio, os índices de desmatamento no ano de 2003 e 2004 foram bastante elevados: $1.858 .000 \mathrm{e}$ 1.814.302 hectares, respectivamente, o que perfaz um aumento de $42,7 \%$ em relação ao ano de 2002. É conveniente ressaltar que, do total desmatado no período de

\section{Tabela 2: Média de desmatamentos em Mato Grosso antes de depois do licenciamento}

\begin{tabular}{|l|r|}
\hline Média do desmatamento $1993-1999$ & 1.283 .785 ha. \\
\hline Média do desmatamento $2000-2002$ & 672.968 ha. \\
\hline Média do desmatamento $2003-2004$ & 1.836 .477 ha. \\
\hline
\end{tabular}

Dados: Fema, 1993 a 2005 
2003, somente 500 mil hectares haviam sido autorizados pela antiga Fundação Estadual de Meio Ambiente . $^{8}$

A avaliação do instrumento coordenada pelo Instituto Socioambiental (ISA), a pedido do Ministério do Meio Ambiente, em 2005, confirma com números o que vinha sendo observado empiricamente por meio dos dados crescentes de desmatamentos no estado. Segundo o relatório, os desmatamentos nos anos de 2003 e 2004, dentro das reservas legais, foram praticamente seis vezes maiores que em outras áreas protegidas, como terras indígenas e unidades de conservação. Além disso, o estudo mostrou que 48,5\% dos desmatamentos em reservas legais nesse período aconteceram em propriedades licenciadas em 2003.

Avaliando preliminarmente os eventos mencionados, pode-se inferir que dois fatos foram determinantes para os resultados do desmatamento, o que leva a um pressuposto sobre a descentralização florestal:

- sobre o avanço do desmatamento por dois anos consecutivos após 2002, pode-se inferir que o mercado influenciou de forma mais determinante, haja vista que, em 2003 e 2004, a cultura da soja, commodity muito produzida no estado, teve preços recordes dentro de um histórico de 26 anos anteriores, contribuindo efetivamente para o avanço da fronteira pecuária ao norte do estado';

- sobre o desmatamento em áreas licenciadas, pode-se inferir que a legislação parece ter "perdido sua força de coerção". Isso pode estar relacionado à chegada, em 2002, de um governo muito ligado à cadeia da soja, o que concorre para o potencial perigo de "flexibilizar" as políticas públicas em benefício do agronegócio. Nesse sentido, Alencar e outros (2004) observam que: “...a experiência da Fema mostrou a necessidade de se manter, pelo menos parcialmente, o sistema de monitoração e fiscalização do desmatamento na Amazônia sob controle e/ou avaliação do governo federal. Uma descentralização desse controle poderá colocar a legislação federal sob influência das mudanças políticas no âmbito estadual e municipal" (p. 54).

"Uma descentra-

lização, com transferência total de responsabilidades, como ocorreu para o Mato Grosso, em estados que ainda possuem fragilidade institucional, administrativa e política, não pode acontecer sem uma ação compartilbada efetiva com o governofederal".

Jordan (2000) aponta uma situação que pode nos remeter à questão florestal no Brasil, sobretudo, quando se pensa na Amazônia. Segundo ele, os economistas do bem-estar, focando a análise na subsidiariedade, sugerem que a problematização/resolução das externalidades sejam dirigidas ao nível em que elas podem ser internalizadas. Em algumas áreas, como mudança climática, por exemplo, essa linha 
de argumentação pede uma decisão em nível internacional, afastando a decisão do cidadão comum, o que já seria diferente em uma situação de poluição de um rio que faz fronteira com dois países. De toda forma, percebe-se que haverá sempre o dilema, segundo o autor, entre democracia participativa (decisão mais próxima do cidadão por meio do voto) e eficiência na regulação (decisão tomada em outras instâncias e com critérios mais técnicos).

Assim, essa argumentação remete à seguinte questão: a quem interessa a conservação do bioma amazônico? Pensando no exemplo anterior, será que somente interessa à população local conservar as florestas do Estado do Mato Grosso? Se interessa a todos a manutenção das florestas, a competência administrativa deveria estar somente a cargo do estado?

A literatura sobre biodiversidade e mudanças climáticas, entre outros temas, mostra amplamente que a conservação dos biomas, bem como as políticas para manejá-la, interessa aos níveis supranacionais, nacionais, regionais e locais. Nesse ponto, uma descentralização, com transferência total de responsabilidades, como ocorreu em 2006 para o Mato Grosso, em estados que ainda possuem fragilidade institucional, administrativa e política, não pode acontecer sem uma ação compartilhada efetiva com o governo federal.

A ação conjunta, mesmo com a descentralização das competências, deve promover um processo sinérgico dos poderes e esferas envolvidos. Novos espaços devem ser criados e efetivados. Caso contrário, essa ação tende a gerar perda de legitimidade para a esfera estadual que, sem governança apropriada, precisa fazer algo que a esfera federal não conseguiu. Por outro lado, esse tipo de descentralização, traduzida somente como "transferência de responsabilidades", pode muito bem parecer omissão do poder federal, o que também causa a impressão de desregulação e igualmente de perda de legitimidade, não só nacionalmente, mas internacionalmente.

Concluindo as duas questões levantadas no início deste texto, parece que há o risco de a descentralização, pelo menos no curto e médio prazos, transformar-se em uma armadilha para a inoperância. Nos níveis locais, não se realizam as ações adequadamente, porque não há recursos humanos e financeiros (sobretudo); nos níveis estadual e federal, argumenta-se em favor de uma administração mais próxima aos cidadãos como forma de legitimar os governos. À medida que transferem as responsabilidades, eximem-se sobremaneira do papel de coordenador/supervisor.

Nessa dinâmica, a hipótese de que a descentralização constitui um processo mais propriamente vertical (de cima para baixo) do que horizontal parece ser bem razoável. Isso leva a supor que a descentralização na política e na gestão ambiental brasileira está sendo uma transferência de problemas com soluções pouco claras nos âmbitos regionais e locais e sem a devida criação de novos espaços (efetivos) de compartilhamento com o poder federal. Nesse ponto, o texto deixa uma questão em aberto: a coordenação desse processo subsidiário falha ou inexiste por parte do governo federal?

\section{Conclusão}

O texto retratou a dinâmica da reforma do Estado. Da abordagem centralizadora e soberana, o Estado transformou-se em uma estrutura mais descentralizada, mantendo uma relação cada vez mais intensa com os níveis supranacionais e subnacionais. O modelo que serve de inspiração é o Estado em rede. 
Os princípios que norteiam esse modelo são a descentralização, a coordenação do governo federal e a participação social.

A partir dos conceitos de subsidiariedade e de governança, chega-se a uma premissa para a descentralização: só é possível realizar a subsidiariedade onde há sustentabilidade institucional (capacidade financeira e administrativa) para tal. Somente desse modo, as esferas regionais, locais e a nacional conseguirão governabilidade (legitimidade) para suas ações e tomada de decisões.

$\mathrm{Na}$ política e gestão ambiental brasileira, verifica-se um movimento dos estados e municípios em torno da descentralização. Isso reflete-se na quantidade de municípios com estruturas institucionais na área ambiental ligadas às prefeituras. Contudo, ainda há muitos desafios a serem superados no processo de descentralização. Parece haver uma clara assimetria entre o desejo de muitos municípios (sobretudo os menores) em não assumir a gestão ambiental municipal e o desejo de o estado em repassá-la. Percebe-se uma indução do estado para que esse processo se concretize de forma vertical (top-down) nos municípios. O grande problema, persistindo esse formato, será a armadilha da inoperância, pois os municípios esbarram na falta de recursos (administrativos e financeiros) para execução efetiva das políticas. Além disso, dois problemas evidenciam-se na arena da sociedade civil: primeiro, ela não consegue exercer o controle efetivo sobre as ações políticas governamentais e, segundo, muitas das organizações não-governamentais são cooptadas pelos dirigentes do poder público, sobretudo, em municípios menores.

No âmbito da gestão florestal, a experiência do Mato Grosso mostra que, sem uma efetiva coordenação do governo federal com a criação de novos espaços de ação conjunta, a descentralização corre o risco de parecer mais uma omissão do poder central do que propriamente uma conquista democrática dos estados e seus cidadãos ou uma melhoria da gestão ambiental.

A descentralização irá realmente tornar-se uma conquista de autonomia dos estados e municípios na gestão de seus recursos naturais à medida que passa a existir pressão social. Portanto, em primeiro lugar, o cidadão precisa saber da possibilidade de descentralização, o poder público federal e estadual precisam compartilhar e estimular o processo e os espaços institucionalizados de participação devem ser criados para efetivamente funcionarem. Por fim, os conselheiros estaduais/municipais devem ser capacitados e envolvidos com a gestão social dos recursos ambientais. Eles são peças-chave para a promoção da gestão nos níveis regionais e locais. Sem eles, mudar-se-á a esfera governamental, mas os problemas serão sempre os mesmos.

(Artigo recebido em janeiro de 2007. Versão final em março de 2007) 


\section{Notas}

1 Governabilidade e governança são conceitos confundidos com freqüência. A capacidade política de governar ou governabilidade deriva da relação de legitimidade do Estado e do seu governo com a sociedade, enquanto governança é a capacidade financeira e administrativa, em sentido amplo, de uma organização de implementar suas políticas (Bresser Pereira, 1998, p.20).

2 Segundo Moran (2002), pela experiência da auto-regulação na Inglaterra, sobretudo na regulação de importantes profissões como medicina e direito, dos mercados financeiros e de outras áreas relacionadas com contabilidade financeira, esses foram os setores nos quais o sistema de poder privado cresceu dentro do governo.

3 Os princípios citados por Castells (1998) para transformar o Estado em rede são a subsidiariedade, flexibilidade, coordenação, participação, transparência administrativa, modernização tecnológica e retroação da gestão.

4 Uma boa referência do autor, que trata a questão entre o local e o global na perspectiva da gestão urbana é: BorJA, J.; CASTELls, M.. Local y Global: la gestión de lãs ciudades en la era de la información. Espanha: Taurus, 2004.

5 Qualidade política é uma referencia a uma das características que Pedro Demo (2003) chama de pobreza política, aquela que se esconde por trás da material, na qual o sujeito não percebe sua condição de oprimido na construção social e econômica. Seria a falta de criticidade para fazer uma leitura social adequada da realidade.

${ }^{6}$ Após a criação do Ibama em 1989, foram extintas a Sema, Sudepe, IBDF e Sudhevea.

7 Em março de 2006, foi aprovada a lei de gestão florestal, que ainda parece muito recente para ser avaliada e tem sido motivo de muita controvérsia.

8 A fundação foi extinta, sendo criada a Secretária Estadual de Meio Ambiente (Sema). Portanto, quando nos reportarmos no texto à Fema, é importante saber que atualmente constitui a Sema.

9 Para entender melhor a relação fronteira pecuária, soja e desmatamento é importante notar que, embora a maior parte do desmatamento seja efetuada pela expansão da bovinocultura, a soja faz pressão indireta nesse processo, pois ocupa terras que antes eram destinadas ao gado. Esse processo fica mais acentuado em períodos quando o preço da soja é mais alto, como aconteceu em 2003 e 2004.

\section{Referências bibliográficas}

Alencar, Ane (et al). Desmatamento na Amazônia: indo além da emergência crônica. Belém: IPAM, 2004.

Azevedo, A.; Scardua, F. Descentralização da gestão florestal: o (des)caso do Mato Grosso. Trabalho apresentado no III Encontro da ANPPAS. Brasília - DF: 23-26 mai. 2006. Acesso em: <http://www.anppas.org.br/> (GT2). 
Bresser Pereira, L.C. A reforma do Estado dos anos 90: lógica e mecanismos de controle. Lua Nova Revista de Cultura e Política, n. 45, 1998, pp. 49-95.

. Uma nova gestão para um Novo Estado: liberal, social e republicano. Conferência John L. Manion 2001. Ottawa, Canadá: 3 mai. 2001. Acesso em: 1 mar de 2007. <http://www.bresserpereira.org.br/ver_file.asp?id=1220>.

Bursztyn, M. Introdução à crítica da razão desestatizante. Revista do Serviço Público, v. 49, n 1, Brasília: jan/mar 1998.

Bursztyn, Maria Augusta; BurszTYn, Marcel. Integrating the environment and development in the decision - making process. In: Encyclopedia of Life Support Systems. Oxford, UK: Eolss Publishers, 2000.

CASTELls, Manuel. Hacia el estado red? Globalización económica e instituciones políticas en la era da información. In: Seminário Internacional Sociedade e a Reforma do Estado. São Paulo: 26-28 mar. 1998.

Demo, P. Pobreza da pobreza. Petrópolis, RJ: Vozes, 2003.

Fink, D.; Alonso, H. Jr. ; Dawalibi, M. Aspectos jurídicos do licenciamento ambiental. 3a. ed.. Rio Janeiro: Ed. Forense Universitária, 2004.

GODARD, Olivier. A gestão integrada dos recursos naturais e do meio ambiente: conceitos, instituições e desafios de legitimação. In: Gestão de recursos naturais renováveis e desenvolvimento: novos desafios para pesquisa ambiental. Weber, J; VIeIrA, P.F. (orgs.) São Paulo: Cortez, 1997.

IBGE. Perfil dos municípios brasileiros: gestão publica, 2004/ IBGE Coordenação de população e indicadores sociais. Rio de Janeiro: IBGE, 2005, 133 p.

ISA/MMA. Sistema de licenciamento ambiental rural em propriedades rurais do estado do Mato Grosso: analise e lições na sua implementação. Projeto Pnud: Bra 98/005. Brasília: MMA, 2005 (no prelo) (participação do ICV).

Jordan, A. Subsidarity and environmental policy: wich level of government should do what in the Eurorean Union? CSERGE Working Paper GEC 99-13. University of East Anglia, 2000.

Moran, Michel. Review article: understanding the regularoy state. B. J Pol. 32, Cambridge University Press, 391-413, 2002.

OliveIrA, Inagê Assis. Introdução à legislação ambiental brasileira e licenciamento ambiental. Rio de janeiro: Lúmen Júris, 2005.

SANTos, Boaventura de Sousa. A reinvenção participativa e solidária do Estado. In: Seminário Internacional Sociedade e a Reforma do Estado. São Paulo, 26-28 mar. 1998.

SCARduA, F. P. Governabilidade e descentralização da gestão ambiental no Brasil. 2003. 237 p. (Tese de Doutorado) pelo Centro de Desenvolvimento Sustentável da Universidade de Brasília. Scardua, Fernando; Bursztyn, Maria Augusta. Descentralização da política ambiental no Brasil. Sociedade e Estado. Brasília, v.18, n.1/2, jan./dez. 2003. 


\section{Resumo - Resumen - Abstract}

A reforma do Estado, a emergência da descentralização e as políticas ambientais Andréa Azevedo, Richard Pasquis e Marcel Bursatyn

No contexto da reforma do Estado brasileiro, a descentralização das competências políticas e administrativas na arena ambiental tem se mostrado um processo dinâmico. Muitas instâncias locais já respondem pela questão ambiental. No entanto, isso não significa mais competência administrativa, sustentabilidade institucional, tampouco participação democrática. Dois casos de política ambiental são retratados no texto: o licenciamento industrial pelos municípios brasileiros e o a gestão florestal pelo Estado do Mato Grosso. A descentralização do licenciamento ambiental para o âmbito municipal ainda parece frágil em municípios menores, em um processo que parece ser induzido pelo Estado e não pelo controle social local. Em relação à política florestal, o caso do Mato Grosso é emblemático. Ele mostra que a cooperação com o poder público federal e, em determinados momentos, sua coordenação são de suma importância para que as políticas públicas ambientais não fiquem à mercê de governos estaduais, que podem enviesá-las em favor do "desenvolvimentismo", nem percam a legitimidade adiante da fragilidade financeira e institucional dos órgãos ambientais locais.

Palavras-chaves: descentralização, sustentabilidade institucional, política ambiental.

La reforma del Estado, la emergencia de la descentralización y las políticas ambientales Andréa Azevedo, Richard Pasquis y Marcel Bursztyn

Ante la reforma del Estado brasileño, la decentralización de las competencias políticas y administrativas en el ámbito ambiental se han mostrado un proceso dinámico. Muchas de las instancias locales ya responden por la cuestión ambiental. Sin embargo, eso no significa competencia administrativa, sustentabilidad institucional, tampoco participación democratica. En este estudio se presentan dos casos de política ambiental: el licenciamiento industrial por parte de los municipios brasileños y la gestión forestal por parte del Estado de Mato Grosso. La descentralización del licenciamiento ambiental para el nivel municipal todavia se muestra frágil en los municipios más pequeños, debido a que el proceso aun está controlado por el estado por encuanto que la sociedades locales tienen menos participación. En relación a la política forestal, el caso del Estado de Mato Grosso demuestra que la cooperación y, en ciertos momentos, la coordinación del poder público federal determinan la vulnerabilidad de las políticas ambientales. Esto es debido a que los intereses "desarrollistas" de gobiernos estaduales pueden influenciar dichas políticas. Por otra parte, la fragilidad financiera y institucional de los órganos ambientales locales pueden también influenciarlas.

Palabras claves: descentralización, sustentabilidad institucional, políticas ambientales.

\section{State reform, emergence of decentralization and environmental policies}

Andréa Azevedo, Richard Pasquis and Marcel Bursatyn

Mirroring the reform of the Brazilian State, the decentralization of administrative and political competences in the environmental arena has been a dynamic process. Many local governments and agencies already hold responsibility for environmental issues. However, it does not mean stronger administrative competency, institutional sustainability or wider democratic participation. Two cases of environmental policy are described here: the industrial licensing carried out by Brazilian municipalities and the State of Mato Grosso's forest management. The decentralization of environmental licensing to the municipal level still seems to be fragile process in small municipalities, 
since it is likely to be induced by the State rather than by the local community. Regarding the forest policy, the case of Mato Grosso is emblematic: it shows that cooperation and, at times, coordination of the federal government is of great importance in order to assure the independence of environmental public policies from state governments that are biased in favor of agro-industries, as well to guarantee their legitimacy, weakened by the institutional and financial fragility of the local environmental institutions.

Keywords: decentralization, institutional sustainability, environmental policy.

Andréa Azevedo

Mestre em Gestão Econômica do Meio Ambiente (ECO/ UnB) e doutoranda em Desenvolvimento Sustentável pelo CDS/UnB; docente da Faculdade do Sul do Mato Grosso (FACSUL/CESUR). Bolsista CAPES. Contatos: <aaabio@terra.com.br; aazevedo@unb.br>

Richard Pasquis

Doutor em Geografia pela Universidade de Paris VII; pesquisador do CIRAD (França) e pesquisador-visitante do Centro de Desenvolvimento Sustentável da Universidade de Brasília. Contato: <pasquis@terra.com.br>

Marcel Bursztyn

Doutor em Desenvolvimento Econômico e Social pela Universidade Paris I; professor adjunto da Universidade de Brasília (Departamento de Sociologia e Centro de Desenvolvimento Sustentável). Contato: <marcel@unb.br> 